We thank the Ministry of Supply (Air) and the Royal Society for grants for equipment, and Imperial Chemical Industries, Ltd. (Explosives Division), for the research maintenance of one of us (O.A. G.).

Note added in proof (October 8). Recently, Ubbelohde et al. ${ }^{5}$ have published results on the effect of grit. Under the conditions of their experiments they did not observe an increase in sensitivity unless the hardness of the grit exceeded 4 on the Moh scale. They find supporting evidence for hot spot initiation in that the sensitivity with hard grit particles is influenced by the melting point of the anvil.

\section{F. P. BOWDEN}

\section{O. A. Gurton}

Research Group on the Physics and

Chemistry of Rubbing Solids,

Department of Physical Chemistry,

$$
\begin{aligned}
& \text { Cambridge. } \\
& \text { May } 27 .
\end{aligned}
$$

May 27.

${ }^{1}$ Bowden, F. P., Stone, M. A., and Tudor, G. K., Proc. Roy. Soc., A, 188, 329 (1947)

${ }^{2}$ Bowden, F. P., Mulcahy, M. F. R., Vines, R. G., and Yoffe, A., Proc. Roy. Soc., A, 188, 291 and 311 (1947)

${ }^{3}$ Taylor, W., and Weale, A., Proc. Roy. Soc., A, 138, 92 (1932).

'Bowden, F. P., and Gurton, O. A., Nature, 161, 348 (1948).

${ }^{5}$ Phil. Trans. (Aug. 10, 1948).

\section{Dielectric Properties of Mixed Barium and Strontium Titanates at $10,000 \mathrm{Mc}$./s.}

MFasurements have been made of the complex permittivity $\left(x^{\prime}-j x^{\prime \prime}\right)$ of a series of mixed barium and strontium titanates at $9,450 \mathrm{Mc} . / \mathrm{s}$. and $20^{\circ} \mathrm{C}$. by a technique, already described ${ }^{1,2}$, which employs a wave-guide containing a multilayer dielectric slab.

The variation of $x^{\prime}$ and $\tan \delta\left(=\varkappa^{\prime \prime} / x^{\prime}\right)$ at $9,450 \mathrm{Mc} . \mathrm{s}$. is shown in Fig. 1, and also that of $x^{\prime}$ at $1.5 \mathrm{Mc} / \mathrm{s}$., for purposes of comparison. The value of $\tan \delta$ at $1.5 \mathrm{Mc} . \mathrm{s}$. is of the order 0.01 throughout.

It is well known that the addition of strontium titanate to barium titanate lowers the temperature of the Curie point by an amount proportional to

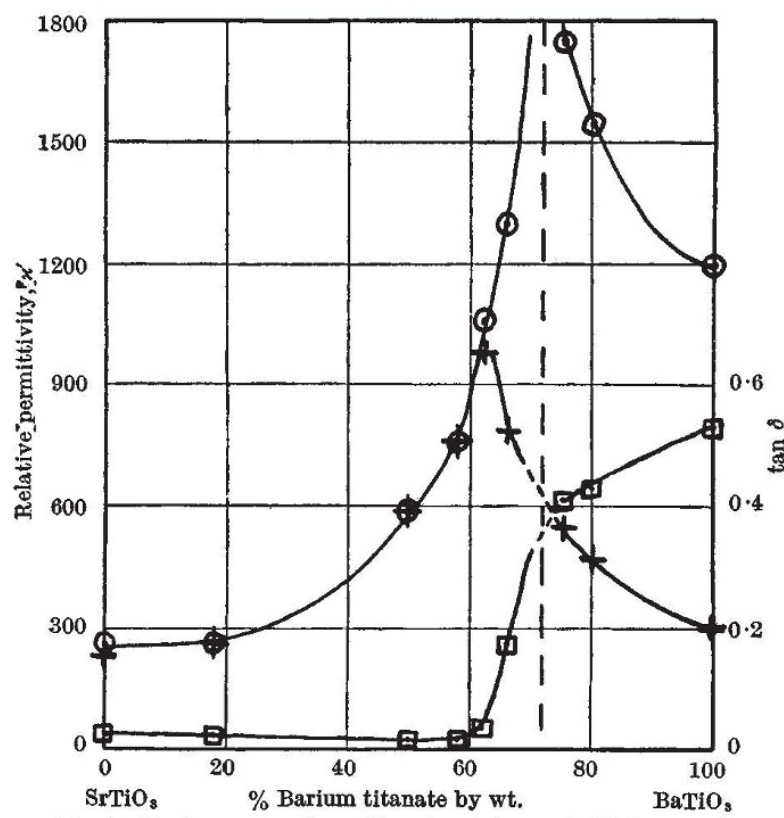

Fig. 1. Barium - strontium titanate mixtures at $20^{\circ} \mathrm{C}$. $O, x^{\prime}$ at $1.5 \mathrm{Mc} . / \mathrm{sec}$. ; +, $x^{\prime}$ at $9,450 \mathrm{Mc} / \mathrm{sec}$; $\square, \tan \delta$ at $9,450 \mathrm{Mc} . / \mathrm{sec}$. the percentage of strontium ${ }^{3}$. The Curie point occurs at $20^{\circ} \mathrm{C}$. for the composition 72 per cent $\mathrm{BaTiO}_{3}$, 28 per cent $\mathrm{SrTiO}_{3}$. The marked variation in permittivity which occurs at $1.5 \mathrm{Mc} / \mathrm{s}$. for 72 per cent $\mathrm{BaTiO}_{3}$ is considerably modified at $9,450 \mathrm{Mc} / \mathrm{s}$. and results for the compositions 66 and 75 per cent $\mathrm{BaTiO}_{3}$, lying closely on either side of this point, suggest that there is no great perturbation in the dielectric properties, although this has not been closely investigated. The dispersion in permittivity suddenly becomes appreciable, and the loss tangent rises rapidly for concentrations of barium titanate well below that at which the material becomes permanently polarized.

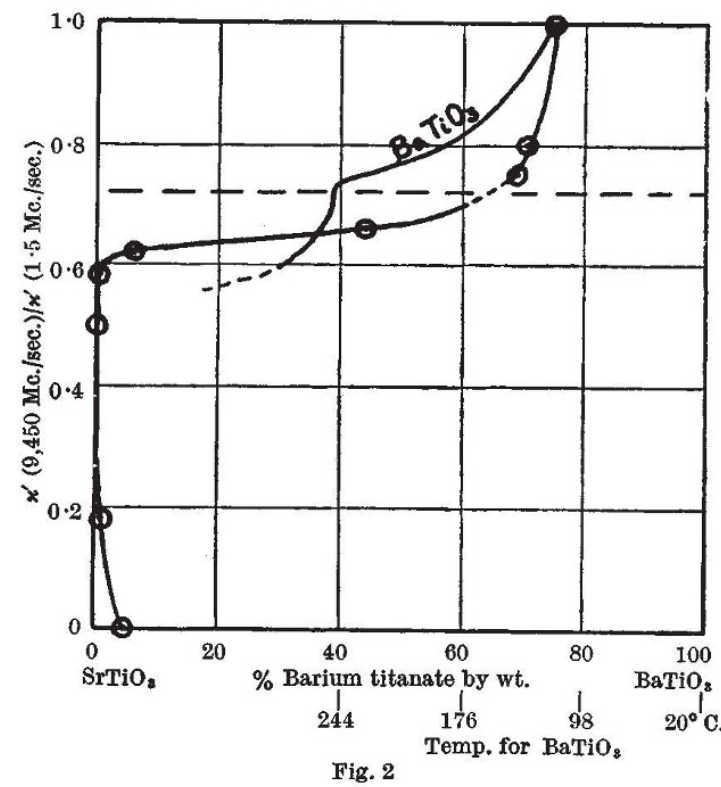

An alternative way of showing the dispersion is to plot $\frac{x^{\prime}(\text { at } 9,450 \mathrm{Mc} / \mathrm{s} .)}{x^{\prime}(\text { at } 1.5 \mathrm{Mc} . / \mathrm{s} .)}$ versus composition as in Fig. 2.

On the same figure is plotted the result for barium titanate alone, at variable temperature ${ }^{2}$, where the temperature scale is related to the composition of the mixed titanate by the shift in the Curie point mentioned above. The essential similarity of the two curves may be noted, and also the fact that in both cases the dispersion is closely associated with the permanently polarized condition.

Incidentally, the material with composition 56 per cent $\mathrm{BaTiO}_{3} 44$ per cent $\mathrm{SrTiO}_{3}$ having $x^{\prime}=760$ and $\tan \delta=0.02$ at $9,450 \mathrm{Mc} / \mathrm{s}$. and $20^{\circ} \mathrm{C}$. should be of considerable technical importance in microwave work. The maximum permittivity value observed was 990 with $\tan \delta=0.04$ at a composition of 62 per cent $\mathrm{BaTiO}_{3} 38$ per cent $\mathrm{SrTiO}_{3}$.

I wish to thank Mr. Popper, of Philips Electrical, Ltd., for providing suitable ceramic materials.

Electrical Engineering Department, J. G. Powrens

Imperial College of Science and Technology, London, S.W.7.

Sept. 9.

${ }^{1}$ Powles, J. G., Nature, 161, 25 (1948).

2 Powles, J. G., Nature [162, 614 (1948)]. "Reddish, W., and Jackson, W., Trans. Faraday Soc., "Dielectrics", 